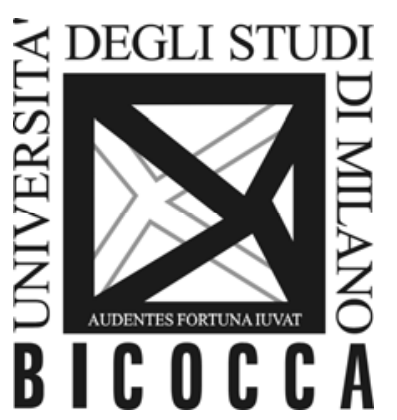

\author{
DEPARTMENT OF ECONOMICS, \\ MANAGEMENT AND STATISTICS \\ UNIVERSITY OF MILAN - BICOCCA
}

DEMS WORKING PAPER SERIES

Extension Services, Production and Welfare:
Evidence from a Field Experiment in Ethiopia

Valentina Rotondi, Jacopo Bonan, Stefano Pareglio

No. 312 - October 2015

Dipartimento di Economia, Metodi Quantitativi e Strategie di Impresa

Università degli Studi di Milano - Bicocca

http://dems.unimib.it/ 


\title{
Extension Services, Production and Welfare: Evidence from a Field Experiment in Ethiopia
}

\author{
Jacopo Bonan, ${ }^{*}$ Stefano Pareglio, ${ }^{\dagger}$ Valentina Rotondi ${ }^{\ddagger}$
}

October 28, 2015

\begin{abstract}
The paper assesses the impact of a small-scale agricultural extension project implemented in rural Ethiopia and aimed at introducing the cultivation of horticultural gardens along with some innovative techniques, products and inputs. Our main outcome of interest is the level of adoption of new horticultural products. We also assess the consequent impacts on the level of revenues from sale and diet diversification. We use a mixed impact evaluation design combining across-villages comparisons, through differencein-differences estimations, with a within village randomized control trial. To this aim, we make use of micro-data collected through surveys administered to 602 households in two time periods (2013 and 2014). We find that the project contributes to production diversification as the number of households growing vegetables increases by about $30 \%$. Overall, such changes do not seem to influence in a relevant way the total revenues from sales of agricultural products and do not consequently affect household welfare. We do not find significant changes in the consumption of vegetables and only marginal increase in fruit uptake. This leads to an overall irrelevant impact on diet diversification.
\end{abstract}

Keywords: Rural Development, Extension Services, Home Gardening, Food Security, Nutrition

JEL classification: D04, O13, Q16

*Department of Mathematics and Physics, Catholic University of the Sacred Heart, Brescia, LabExpo (Giangiacomo Feltrinelli Foundation) and FEEM

${ }^{\dagger}$ Department of Mathematics and Physics and CRASL, Catholic University of the Sacred Heart, Brescia

${ }_{\ddagger}$ Corresponding author. Department of Economics, Catholic University of the Sacred Heart and Department of Economics, University of Milan-Bicocca, Milan.

Acknowledgement We acknowledge the financial support of Fondazione punto.sud and Fondazione Giangiacomo Feltrinelli. We are very thankful to CIAI staff in Milan and Addis Ababa: Chiara Biffi, Samuela Venturini, Marta Volpi, Yesuf Mohammed. We are indebted to Anna Pasotti and Alessandro Runci for valuable research assistance. We thank Federico Bastia, Fabrizio Alberizzi, Luca Stanca, Mariapia Mendola, Laura Pagani, Stefania Ottone, Claudio Lucifora and Gianluca Femminis for valuable comments. 


\section{Introduction}

A large proportion of the world's poor live in rural areas and for $70 \%$ of this population agriculture is the main source of income and employment (FAO et al., 2014). In most Sub-Saharan countries agriculture and its associated industries are essential tools to foster a dynamic and inclusive growth and to reduce mass poverty and food insecurity. However, using agriculture as the basis of economic growth requires a productivity revolution in smallholder farming (World Bank, 2007). This revolution has not yet taken place in SubSaharan Africa where, despite an increase in agricultural productivity, the agricultural sector lags behind (Evenson, 2003; Krishnan and Patnam, 2014). Empowering rural people by rising their productivity has been and still is an important focus of the agricultural economics research agenda (Udry, 2010; Jack, 2011; Taye, 2013) and, at the same time, it has been the main goal of several development programs (Christiaensen and Demery, 2007).

Low agricultural productivity may be caused by market incompleteness such as credit constraints (Fink et al., 2014; Croppenstedt et al., 2003; Rosenzweig and Wolpin, 1993), imperfect financial and insurance markets (Kazianga and Udry, 2006; Conning and Udry, 2007), weak property rights (Goldstein and Udry, 2008), lack of knowledge and information regarding new technologies, products and methods and their role in enhancing agricultural productivity. Several countries have tried to tackle informational constraints through agricultural extension services, with the goal to include information transfer from the global knowledge base and from local research to farmers, by enabling them to clarify their own goals and possibilities, educating them on how to make better decisions, and stimulating desirable agricultural development (Van der Ban and Hawkins, 1996; Birner et al., 2009).

Despite decades of investment in agricultural extension programs, a general agreement regarding their effectiveness is still lacking and the empirical evidence often gives mixed results, reflecting differences in how the programs are delivered and in the circumstances of beneficiaries (Anderson and Feder, 2007; Aker, 2011). Several scholars show that extension programs have a positive effect on several rural livelihoods including knowledge, skills, productivity, consumption, and poverty reduction (e.g., Dercon et al. 2009, Godtland et al. 2004, Praneetvatakul and Waibel 2008, Romani et al. 2003, Maffioli et al. 2011, Owens et al. 2003, Davis et al. 2012) while some others find only negligible achievements (e.g., Rivera et al. 2001, Ashraf et al. 2009b, Maffioli et al. 2013). In general, these findings differ according to the technology and context of project implementation, while the estimation of the impact of these programs is often hampered by attribution issues, endogeneity and selection bias. The causal interpretation of the results can be challenging and understanding how new technologies and good practices are (not) adopted by farmers is still an open issue (Udry, 2010). For this purpose, the imple- 
mentation of monitoring and evaluation tools is increasing at all levels, with the aim to provide impact assessments. These can be used by implementers to improve the quality, efficiency and cost-effectiveness of interventions, as the focus is on the results, rather than on the inputs and outputs. Moreover, measuring program impacts raises public awareness and promotes accountability by stakeholders, while, at a more global level, it contributes to building knowledge on what does and does not work to reduce poverty, improve welfare and sustain development.

Assessing the impact of extension services requires to address the attribution issue through the use of identifications which tackle endogeneity problems. Endogeneity may arise from the fact that allocation of extension efforts may not necessarily be random across or within localities. For example, targeting more advantaged (disadvantaged) areas with extension services may respond to different policy aims, but would bias impact estimations upwards (downwards). Moreover, it could be the case that farmers' ability or motivation determines their participation to some activities. This would lead to overestimations of impacts if only more motivated and skilled farmers benefit from extension activities. Few rigorous impact evaluations of extension services in developing countries explicitly tackle the issue of endogeneity and self-selection (Aker, 2011). Different empirical strategies have been adopted, such as quasi-experimental techniques (e.g Godtland et al. 2004), panel data (e.g Maffioli et al. 2011), instrumental variables (e.g Dercon et al. 2009) and randomized experiments (e.g., Ashraf et al. 2009a). Given the severe limitations in data collection and rigorous research designs, methodological heterodoxy is deemed essential in the study of technological change and agricultural productivity growth (Barrett and Carter, 2010).

In this paper we assess the effect of an agricultural extension project implemented in a village in Ethiopia between 2013 and 2014 and aimed at introducing the cultivation of horticultural gardens along with some more innovative techniques, products and inputs. The project consisted of a series of extension activities including training sessions with the preparation of a show-garden, the distribution of inputs such as vegetable seeds and working tools. Households then received some technical follow-up visits by local development agents. The intervention was targeted to vulnerable households. In accordance with the project's theory of change, our main outcome of interest is the level of adoption of new horticultural products. This specific outcome is crucial to create a new condition where the increased availability of horticultural products may contribute to a more diversified diet and new revenues from sale of products.

The impact of extension programs on agricultural innovation, production and welfare have been thoroughly studied in the literature. Maffioli et al. (2011) evaluate the effectiveness of the Farm Modernization and Development Program in Uruguay and find a positive effect of the program on 
improved production techniques, such as plantation density and the rate of adoption of certified varieties. Maffioli et al. (2013) find evidence that extension programs increased plantation density. However, they find no evidence of the program's impact on yields for the period under study. Owens et al. (2003) find that, after controlling for innate productivity characteristics and farmers' ability, access to agricultural extension services raises the value of crop production by about $15 \%$. A positive impact of extension services on productivity is also found in Romani et al. (2003) in the Ivory Coast. Dercon et al. (2009) assess the impact of public investments in agricultural extension and road quality on consumption growth and poverty rates in rural Ethiopia. Results suggest that receiving at least one extension visit reduces headcount poverty by $9.8 \%$ and increases consumption growth by $7.1 \%$. Davis et al. (2012) estimate the effect of a particular form of agricultural extension service in East Africa, delivered through farmer field schools, on the economic and production spheres. Results show that farmer field schools have a positive impact on production and income among women, low-literacy, and medium land size farmers. Ashraf et al. (2009) evaluate the effect of an extension project implemented in Kenya and attempting to support farmers in adopting market export crops by relieving financial and informational constraints. Results suggest that after one year the program led to an increase in the production of export-oriented crops and lower marketing costs; this translated into household income gains for new adopters.

The present work contributes to this literature by exploiting a mixed impact evaluation design combining across-villages comparisons, through difference-in-differences (DID) estimations, with a within village randomized (WVR) control trial design. To this aim, we make use of micro-data collected through surveys administered to 602 households in two time periods (2013 and 2014) to compare the outcomes of three groups: a random selected pool of project beneficiaries in the treated village, a random pool of non-treated farmers in the same area and a pure control group in another village with similar characteristics. We first exploit a DID design to compare changes in the dependent variables of interest between treated and control village across time, conditional on observable characteristics. We also exploit a WVR design and implement an instrumental variable (IV) approach to solve the problem of missing or unknown controls, using the random assignment to treatment and control group as instrument. These exercises, taken together, give us upper and lower-bound estimates of project impacts.

This paper partly contributes also to the literature on the effect of extension services on nutritional outcomes whose link with agricultural interventions has been widely reviewed (see for instance Berti et al. 2004, Girard et al. 2012, Masset et al. 2012, Ruel and Alderman 2013).

Our findings indicate that the project has contributed to production diversification as the number of households growing vegetables increases by 
about 30 percentage points, corresponding to a $78 \%$ increase with respect to the baseline value. We also find a significant increase in revenues from sale of vegetables and, partially, fruits. However, overall, such changes do not seem to influence total revenues from sales of agricultural products in a relevant way. As far as nutrition is concerned, our results indicate that the intervention did not produce significant changes in the consumption of vegetables and only a marginal increase in fruit uptake. This leads, to an overall irrelevant impact on diet diversification. We provide some possible contextual reason for such results.

The remaining part of this paper is organized as follows: section two presents the context and the project intervention. Section three presents sampling strategy and estimation methodology. Section four reports the results and discussion of the impact evaluation exercise while section five concludes.

\section{Context and project intervention}

Ethiopia is the second-most populous country in Sub-Saharan Africa with a population of about 90 million (Malik, 2013) and a population growth rate of 2.6\% (Michael and Lars Christian, 2013). One of the world's oldest civilizations, Ethiopia is also one of the world's poorest countries with a per capita income of 470 dollars, substantially lower than the regional average (Gross National Income, Atlas Method). The Ethiopian economy has experienced strong growth over the past decade, averaging $10.9 \%$ per year in 2004/05$2012 / 13$ compared to the regional average of $5.3 \%$. Expansion of the services and agricultural sectors account for most of this growth, while manufacturing sector performance was relatively modest. Agriculture remains mainly traditional and employs more than $80 \%$ of the national labor force, accounting for $45 \%$ of GDP and $85 \%$ of export revenues. Ethiopia is an interesting case study with respect to extension services. In fact, the Ethiopian government has directed for a long time its growth strategy on agriculture by investing close to 1\% GDP on these programs (DFID, 2014).

The Siraro district is located in the south-west of the Federal state of Oromia, with a population of around 167,785 inhabitants (Agency, 2014). Siraro is a typical area of the Ethiopian plateau, characterized by an altitude ranging from 1500 to 2300 meters above sea level. 51.8\% of land is arable or cultivable while $1.8 \%$ is dedicated to pasture and $4.7 \%$ is characterized by forests. The remaining $41.6 \%$ is considered swampy, degraded or otherwise unusable. Agriculture is the main activity in the district especially in remote areas. In line with the rest of the country, in the Siraro district there are two crop production seasons referred to as the meher (or main) and belg (short

http://www.worldbank.org/en/country/ethiopia 
rain). The meher season starts in June and extends to October with the highest concentration in July and August. The belg season most often refers to a small but timely rain season, which normally occurs from February to May. The study area includes two villages in the Siraro district, Ropi and Alemtena, located about $10 \mathrm{Km}$ apart. Life expectancy is around 45 years and average age of the population is 16 years. The villages show a substantial shortage of services (e.g. water supply systems, schools, offices, health services, etc). Considering health, three main problems are reported: malaria, malnutrition and water borne diseases. While malaria is reported only during a few months of the year, water borne diseases and malnutrition cases are present permanently. The incidence of malnutrition appears to be particularly relevant for children.

The project first provided eligible farmers with two training sessions which took place in 2013 and 2014, lasting three days and focusing on horticultural process of vegetables and fruits. The vegetables introduced were cabbage, onion, beetroots and carrot along with papaya. Theoretical sessions about the advantages of vegetable and fruit production to improve household welfare were accompanied by the preparation of show-gardens. A specialist from the local health center was invited to illustrate the nutritional properties of vegetables and fruits. Farmers were also trained about the correct use of pesticides, both natural and chemical, to control for major pests and diseases. Some training about soil fertility management, compost making and post-harvest practices was also provided. Participants had the possibility to receive the seeds of the plants discussed in the training sessions and some agricultural tools (hoes and racks). Upon receiving the training and the inputs, farmers were visited by project staff (in collaboration with the local development office and its experts at district level) in order to receive a technical follow-up on garden maintenance and on the implementation of the techniques explained during the training, such as seed beds preparation, compost and pesticide making, etc. During the visit, a qualitative assessment of the state of the garden and of the implementation of soil fertility management was made by the project staff. The project intervention was designed and implemented by the Italian Center for Children Aid (CIAI), an Italian NGO which has been engaged in cooperation and development activities in Ethiopia since 2003 and which started operating in the municipality of Ropi in 2011. 


\section{Empirical Strategy}

\subsection{Sampling and data}

The project was intended to target 250 farmers, $25 \%$ of which female-headed households, $8 \%$ of model farmers, the rest being male-headed, owning at least some land and household size between 5 and 8 members. The first step of the sampling procedure was the selection of beneficiaries farmers in the treated village, following project guidelines. A list of 545 potential beneficiaries satisfying the required criteria was constructed by field project staff, based on local administrative data. Based on the available information, we stratified the sample with respect to per capita land, dividing total land by household size (which we partitioned in tertiles) and gender of the head. We randomly selected from each cell proportionally in order to reach the targeted composition of beneficiaries, for a total of 250 households. The control group in the treated village was randomly selected from the pool of remaining households for each stratum and was drawn with the same proportion employed for the treatment group. The control group was formed by a sample of 121 households.

For the control group in the control village (Alemtena) we started from a list of 425 farmers provided by local authorities, we adopted the same stratification criteria (using the same threshold levels of per capita land) as in the treated village. The sample included a total of 250 households. Unfortunately, the administrative data on which we based the sampling revealed to be slightly different from the actual data collected through surveys. As a consequence, the composition of eligible beneficiaries was slightly different from the initial project objectives.

The baseline survey was conducted in June 2013 before project activities had started, by 10 local enumerators and it included 485 observations: 244 in the treated village and 241 in the control one. Due to financial constraints, only treatment households in the treated village could be surveyed at the baseline.

15 questionnaires could not be included in the analysis and were discarded due to the low quality of data and unreliability of information. The followup survey was conducted in November 2014. 481 households visited at the baseline could be successfully tracked, of which 242 in the treated village and 239 in the control one. The very small extent of attrition (less than 1\%) and mean comparisons of baseline characteristics between attrited and nonattrited sample lead us to rule out that the final sample of analysis differed significantly from the initial sample of analysis. At the follow-up we also

Farmers officially recognized as the most innovative and more productive in the area by government development agents.

The main reason for the inability to track households is due to change of place of residence of the family 
administered the questionnaire to 121 households in the control group in Ropi.

Questionnaires were administered on paper and in local language to the head of the household. In $93 \%$ of cases the respondent was the head of household; in the remaining cases the wife (or another key informant) answered the questions, due to the unavailability of the head. Quality and coherence of filled questionnaires were checked by research assistants who also dealt with data-entry using Census and Survey Processing System (CSPro). Data were then cleaned and datasets for analysis were created using Stata software. Descriptive statitistics were produced by computing means and differences in means (using Student's t-tests) across different samples.

\subsection{Difference-in-Differences (DID)}

We first estimate the project impact by using the DID estimator. This method compares the change in the dependent variables of interest in the treated village between two points in time, before and after the project implementation, to the change in the same outcomes in the control area, conditional on observed characteristics. DID relies on the assumption that, conditional on observables, the evolution of the outcomes in treated and control areas would have been the same in the absence of the project, or, equivalently, that any difference in the relevant outcomes between treated and control areas due to unobserved factors is fixed over time (e.g Heckman et al. 1997, Abadie 2005). We estimate the effect of the project on the outcome $Y_{i}$ using repeated cross-section data. More explicitly, we estimate the following regression with Ordinary Least Squares (OLS):

$$
Y_{i t}=\beta_{0}+\beta_{1} P_{i}+\beta_{2} t+\beta_{3}\left(P_{i} t\right)+\gamma x_{i}+\varepsilon_{i t}
$$

where $P_{i}$ is a dummy variable equal to one for treatment village (Ropi) and zero for the control one (Alemtena), $t$ is equal to one for post-program and to zero for pre-program. The coefficient attached to the interaction term, $\beta_{3}$, is the parameter of interest and gives the DID estimate of the average effect of the project on outcome Y. $\beta_{0}$ is a constant term, $\beta_{1}$ is the treatment group specific effect which accounts for average permanent differences between treatment and control individuals, $\beta_{2}$ gives the time trend effect common to control and treatment groups, while $x_{i}$ is a vector of head and household observable baseline characteristics including household's characteristics (households' size, number of children below five in the household, size of the land owned), head of the household characteristics (whether the head is female, whether he/she lives in couple, his/her age, his/her grade of

This is also known as the parallel trend assumption and means that unobserved characteristics affecting program participation do not vary over time with treatment status.

(Heckman and Robb, 1985) 
schooling and whether he is a model farmer), participation in the program and in social activities (whether the household has received at least one visit from development agents, whether the household has benefitted from other support programs, whether the household participates in community based organizations (CBO) and whether the head knows any model farmer). Among the controls we also included the average monthly household's income quintiles and a wealth index computed using Principal Component Analysis (PCA) as suggested by Filmer and Pritchett (2001), by aggregating the information on all assets possessed by the households in a single synthetic index.

While the assignment to the treatment has followed some controlled criteria, there are several reasons why the effective treatment status may be the outcome of some selection process, which goes beyond our control and may hinder the impact evaluation exercise. First of all, among eligible farmers treatment provision was not uniform and homogeneous for all the beneficiaries. A non-random sub-sample received inputs in Summer 2013, a larger sub-sample of eligible farmers received it in Spring 2014, while a relatively small amount of individuals did not receive any project intervention. Moreover, it could be that only more motivated farmers have participated in the training session or may have shown interest in receiving as many inputs as possible. The level of farmers' motivation is a typical unobservable variable which may affect both the likelihood of receiving the intervention and the final outcomes of interest, for example the adoption of improved techniques and products. In such case we would not be able to disentangle the effect of farmers' motivation from the effect of the project. It could also be that the project staff decided to put more effort in supporting either more skilled and quick learners, as the task would be easier, or, the more disadvantaged ones (for personal or institutional reasons). Again, it would be hard to dis-

CBOs are non-profit groups working at local level to improve life of residents through the provision of services to their members, such as credit and saving opportunities or reciprocal financial support during moments when extraordinary expenditures are required, such as funerals. They can also be focused on human services, natural environment conservation or restoration, and urban environment safety and revitalization.

Formally, the wealth index uses the first principal component of the set of introduced variables. The use of the first principal component yields a wealth index that assigns a larger weight to assets that vary the most across households so that an asset found in all households is given a weight of zero. The first principal component or wealth index can take positive as well as negative values. The categorical variables expressing house facilities such as toilet and water facilities are transformed into ordinal variables and treated as continuous, as suggested by the literature (Vyas and Kumaranayake, 2006). The items considered in the index are: toilet facilities, drinking water facilities, N. of sleeping rooms in the dwelling, hoes, ploughs, granaries, bikes, motorbikes, mobile phones, big-size animals (donkeys, horses, cattle), mid-size animals (goats, sheep), small-size animals (poultry), beds, tables and chairs, kitchen appliances (jerry cans, pots, pans, fans, stoves), energy sources (batteries, generators), other appliances (sewing machines, iron, wheelbarrow, kettle, radio). 
tinguish the effect of the selective effort from the real treatment effect. Since we cannot rule out that any of such processes occurred in our study, we evaluate the Intention to Treat Effect (ITT) in (1), by considering the overall group of households eligible to receive project activities. The results are therefore being interpreted as the effect of being eligible to participate in the treatment.

Then, in order to check the potential heterogeneous effect of different levels of program take-up we create three categories corresponding to different degrees of program intensity: one corresponds to the uptake of the full package of project activities (participation in training, provision of tools and seeds, at least one technical follow-up visit), the second characterizes farmers who were not exposed to any activity at all while the third is a residual category gathering individuals who were partially exposed to some project activities. Similarly to (1), we estimate the effective treatment effect by OLS:

$$
Y_{i t}=\beta_{1}+\beta_{2} P_{i}+\beta_{3} t+\beta_{4}\left(A P_{i} t\right)+\beta_{5}\left(P P_{i} t\right)+\gamma x_{i}+\varepsilon_{i t}
$$

where $P_{i}$ is a dummy variable equal to one for treatment village (Ropi) and zero for the control one (Alemtena); $A P_{i}$ is a dummy variable equal to one for effective exposure to all project activities, $P P_{i}$ is equal to one for partial intensity of the project, $t$ is equal to one for post-program and to zero for pre-program. The coefficients attached to the interaction terms, $\beta_{4}$ and $\beta_{5}$, are the parameters of interest and give the DID estimates of the effects of different levels of program intensity with respect to not receiving anything. $\beta_{1}$ is a constant term, $\beta_{2}$ captures group specific effects which accounts for average permanent observable differences between assigned treatment and control individuals, $\beta_{3}$ gives the time trend effect common to control and treatment groups, while $x_{i}$ is a vector of head and household observable baseline characteristics as in (1).

We cannot interpret, $\beta_{4}$ and $\beta_{5}$ as unbiased average treatment effects of the project since they incorporate both the true treatment effect and the effect of some unobservables. Unfortunately, we are unable to disentangle the two forces (we lack an exogenous instrument), but we can reasonably suppose that the sign of the bias is positive, meaning that we expect that unobservables, such as farmers skills or curiosity, are positively related to both the uptake of the program activities and outcomes. In fact, qualitative discussions with field project staff allow us to rule out that selection of the most disadvantaged has been in place; conversely, farmers demonstrating interest towards the project tended to be more involved by the project staff. Therefore, we are exclusively able to draw conclusions on outcomes which remain unaffected by the project. In other words, on the one hand when estimates are significant, we cannot conclude anything, due to the impossibility to disentangle treatment effect and positive selection bias; on the other hand, when estimates are not significantly different from zero, we can conclude that the project has not impacted the given outcome. 


\subsection{Within village randomization (WVR)}

The second evaluation methodology relies on the random assignment of potential project beneficiaries in a treatment and a control group within the village of Ropi. Randomization ensures that the two groups are on average homogeneous along all aspects except the exposure to the treatment, and allows us to attribute causal effects of the project to the differences in outcomes observed. We estimate by OLS the following specification on the sample of Ropi in 2014:

$$
Y_{i}=\beta_{0}+\beta_{1} P_{i}+\gamma x_{i}+\varepsilon_{i t}
$$

$P_{i}$ is a dummy equal to one for farmers randomly assigned to receive the project and $\beta_{1}$ reports the Intention to Treat Effect (ITT), our parameter of interest. $x_{i}$ is a vector of observable time-invariant characteristics, including head and household characteristics as in (1).

WVR approach bears the risk of violation of the stable unit treatment value assumption (SUTVA), according to which the treatment status of any unit does not affect the potential outcomes of the other units (noninterference). In fact, the control group may directly or indirectly benefit from the exposure to the treatment, for example through the contact and relationship between project beneficiaries and non-beneficiaries which may lead to imitation processes. Moreover, some project activities, such as show gardens, were implemented in public spaces where access was free for all the villagers. We cannot therefore rule out that spillover effects may have influenced non-beneficiaries outcomes. This fact hinders the attribution of effects to the project. However, we can safely assume that spillovers are likely to be positive, meaning that non-beneficiaries may be either directly or indirectly influenced by the project which may change the behavior in the direction of the purposes of the intervention. The evaluation exercise would then tend to underestimate the effects of the programs. In other words, when significant effects are found, those are likely to be underestimated, being even larger in reality, whereas in case of non-significant effects, we cannot conclude anything, due to the impossibility to disentangle the true impact effect from the spillover effect.

We encountered partial compliance issues in the actual project exposure in Ropi, as some eligible farmers did not receive any benefit from the program, whereas some farmers in the control group actually received some benefits which we can observe, through the questionnaire, beyond the unobservable spillover effects. As previously expressed, the mechanism underlying the effective program uptake is non-random and prone to bias. In order to overcome such a problem, we implement an instrumental variable approach (IV) using as instrument the random assignment to the treatment and con-

As mentioned more extensively in the section on sampling, we do not have baseline data for the control group in Ropi 
trol groups. We compute the Local Average Treatment Effect (LATE), the treatment effect on the population of compliers, as follows:

$$
Y_{i}=\beta_{0}+\beta_{1}\left(\hat{E P_{i}}\right)+\gamma x_{i}+\varepsilon_{i t}
$$

where $\hat{E P_{i}}$ represents the effective treatment exposure and reports the fitted values of the first step regression (using a two stage least squares procedure) in which the effective treatment status is regressed on $P_{i}$, the random assignment to treatment variable.

The main purpose of both DID and WVR approaches is to assess average treatment effects on the outcomes of relevance. However, effects may not be necessarily homogeneous throughout the distribution: there might be some classes of individuals who benefit more or less from the intervention. Throughout both methodologies, we explore the existence of heterogeneous effects across some observable characteristics linked to the extent of household vulnerability, by running regressions as in (1) and (3) on different subsamples linked to the amount of land owned (above and below the median) and the level of wealth (above and below the median of a wealth index).

\section{Results}

\subsection{Descriptive statistics}

\subsubsection{Household characteristics}

Table 1 show the characteristics of household heads and their families measured in 2013, during the baseline survey. Sample differences in initial conditions between the village of Ropi (treated) and Alemtena (control) are reported in column 4 . Lack of significance in sample differences means very similar initial conditions for treatment and control individuals. Since sample selection of households in Ropi and Alemtena was based on limited and possibly imprecise administrative data, the two samples differ along some characteristics. However, DID approach is such that, as long as differences are assumed constant over time, they do not influence the estimation of treatment effects. Conversely, the use of randomization in the sample selection of individuals in treatment and control groups in Ropi should guarantee that the two groups are identical, on average, across observable and unobservable characteristics, as they only differ in the eligibility to receive the treatment.

See Angrist et al. (1996) for more details on the methodology

In the case of Ropi control, variables are measured in 2014. In most cases, the variables reported change very slowly in time and are unlikely to be influenced by the project intervention. As a precautionary measure, we asked respondents to date changes of timevariant variables and to repeat comparison of samples on the same time horizon. Results do not vary significantly. 
In the impossibility to show sample differences at the baseline, because we do not have baseline data for Ropi control, we only present differences of variables which are not supposed to change over time. A successful randomization should lead to no significant differences between treatment and control group, however, small sample problems could determine the presence of significant differences. Differences across samples in Ropi are reported in column 5 .

Agriculture is the main income generating activity: $90 \%$ of the sample works in agriculture, while slightly less than $1 \%$ works in the formal sector as public servant, for private companies or NGOs and $2 \%$ works in the informal sector, for example running small businesses. Data reveal that even those whose main income generating activity is not agriculture spend some time in growing crops. Income is measured as the sum of all monthly income sources of the household. The average income is 454 BIRR (22 USD) in Ropi and 330 BIRR (16 USD) in Alemtena. The difference varies significantly between sub-samples. The wealth index does not differ significantly across groups. Household heads were asked whether they had received any type of agricultural support provided by NGOs or government in the previous seasons and visits by development agents, governmental extension and agricultural support providers employed by local authorities. With respect to these variables, averages seem to diverge between Ropi and Alemtena (measured at the baseline) and between Ropi and Ropi Control (measured at the follow-up).

The average household is composed of six members of whom at least one child is less than 5. Land is owned by farmers in almost all our samples. On average, each household own 0.80 hectares. The difference between the amounts of land owned varies significantly among sub-samples: in Ropi, households owns about 0.15 hectares more than in the comparison groups. Female-headed households are about $20 \%$ in both Ropi and Alemtena, although they are under-represented in Ropi control. Household heads are about 40 years old and and have completed an average of less than 2 years of schooling, however in general in each household at least one member is able to read and to write.

On average, about $10 \%$ of our sample is composed of model farmers. Over $80 \%$ of the farmers know at least one model farmer. Almost all the households in the sample participate, with some members (normally, but not necessarily the head) in community-based organizations (CBOs). About $19 \%$ are members of saving groups, around $78 \%$ participate in funeral groups while $20 \%$ participate in self-help groups. Significant differences in CBOs involvement arise between Ropi and Alemtena.

\subsubsection{Project uptake}

According to data collected during the follow-up survey, 93\% (226 farmers) of households eligible to receive the treatment declared that they had par- 
ticipated in at least one training session organized within the project. For those not participating, the most common reason cited is linked to the fact that they had not been invited or did not know anything about the project. Among attendants, $82 \%$ remembered training and activities on vegetable production, $34 \%$ on soil fertility, $23 \%$ that on pest control and $22 \%$ on diet. $77 \%$ of eligible farmers (187 farmers) received at least one tool for agriculture (plough and watering can), $86 \%$ of them declared that they had used such tools in the current agricultural season. 82\% (199 farmers) declared that they had received seeds but only $52 \%$ had actually used them. $85 \%$ of eligible farmers visited the show-garden at least once. 89\% (213 farmers) received at least one follow-up visit by project staff, on average about 2 visits. $6 \%$ ( 8 farmers out of 121) of the households living in Ropi but not beneficiaries of the project declared that they had participated in some project activities. The garden was visited by $23 \%$ of the control sample in Ropi.

Based on this information, the beneficiaries of the program have been classified in three sub-groups according to their degree of project intervention uptake. Beneficiaries who had undertaken all the project activities (training, received at least one tool for agriculture, visited the show garden at least once and had at least one follow-up visit) constitute $64 \%$ of the beneficiaries. Beneficiaries who had undertaken none of the project activities are $4 \%$ of the sample of beneficiaries. Eligible beneficiaries who had undertaken some are the remaining $32 \%$ of the sample.

No households in Alemtena declared that they had been exposed to treatment activity or visited the show garden in Ropi. Only one farmer in the control village declared that he knew project beneficiaries in Ropi. We can therefore exclude any sort of spillover or contamination between the two villages.

\subsubsection{Agricultural production and revenues from sale}

Table 2 provides a characterization of the agricultural sector in the study area, including both Ropi and Alemtena, and presents the main crops cultivated, their main source of seeds, the use of fertilizer, whether the harvest is sold or self-consumed, measured at the baseline. The most commonly cultivated cereal is corn, grown by $98 \%$ of households. $30 \%$ of households cultivate teff, also known as lovegrass, a particular cereal grown in Ethiopia and Eritrea, where it is used to make enjera, a local substitute for bread. 37\% cultivate millet. Cereals' seeds are normally bought at the market and only to a small extent are already owned by families or come from government and NGOs. Much less common is the cultivation of pulses and vegetables, exception made for haricot beans cultivated by almost $50 \%$ of the households.

Among those receiving some seeds, $86 \%$ received onion seeds, $96 \%$ carrot seeds, $93 \%$ beet-root seeds, $94 \%$ cabbage seeds 
Even for pulses and vegetables most of the seeds are purchased at the market, except for carrot seeds that are provided by NGOs in $60 \%$ of cases. The use of fertilizers is quite common for all types of crops. The most sale-oriented crop cultivated is teff ( $65 \%$ of households declared that they had sold all the yields of the previous season) while only $1 \%$ of the households declared that they had sold the entire harvest of corn.

Tables 3 and 4 provide the initial values of outcome variables referring to season 2012, collected at the baseline in Ropi and Alemtena and the values referring to season 2014. In table 3 agricultural enterprises are grouped by main types (cereals, vegetables, fruits, pulses and tubers). Single differences between Ropi and Alemtena samples for each period are shown in columns 3 and 7, while column 9 reports the double difference, which constitutes a first raw evidence of the impact of the project. We also show differences within the treatment and control samples in Ropi, observed in 2014 (column 8).

The initial level of diversification of the production seems relatively low, confirming the picture drawn from table 2. On average, farmers grow 2 to 2.5 different crops (significantly more in Ropi than in Alemtena). Preliminary descriptive evidence suggests that the project contributed to increase the variety, which reaches 5 products in the treatment group. Cereals are cultivated by the whole sample, with insignificant differences across samples and time. The share of farmers growing vegetables in 2012 is significantly higher in the Ropi treatment (19\%) than in Alemtena (4\%). Shares increase in both samples across time, however such growth is much higher in the Ropi treatment group (the share reaches 81\%), compared to both Alemtena (31\%) and in the Ropi control group (46\%). All the products introduced by the project are influencing the total number of products cultivated which increases as does the share of households cultivating vegetables. In particular, cabbage is grown by $70 \%$ of the households ( $40 \%$ more than in the control group), carrot by $62 \%$ (60\% more than the control group) and beet root by $50 \%$ ( $50 \%$ more than the control group). The share of farmers growing some fruits in the treatment group also increases significantly, compared to both control groups and across time, although the difference is smaller than in the case of vegetables. About half of the sample also cultivates some pulses and tubers. Despite the presence of sample differences between Ropi and Alemtena at the baseline, no significant changes in such enterprises seem to occur in time among the two samples.

We compute a measure of sales revenues for the entire agricultural production and for each crop type. Average revenues from sales range from about 1000 to 2000 birr (48-96 USD) at the baseline. In general, we observe that the crops having the highest weight on revenues are cereals and pulses while fruits and vegetables have a marginal role. Ropi farmers get more revenues from the sale of products both at the baseline and at the follow-up, compared to the control village. A common time trend leading to higher 
revenues in the second period in both locations is observed. However, for cereals, vegetables and fruit the increase is higher in the treatment group in Ropi (column 9). Compared to the control sample in Ropi, significantly higher revenues from the sale of vegetables are found in the treatment sample (column 8). We cannot draw any rigorous conclusion on the imact of the intervention from such an exercise which remains mainly descriptive and we postpone the discussion of treatment effects to the next sections.

\subsubsection{Food consumption and diet diversification}

Table 4 shows descriptive statistics on food and nutrition habits. Following international standards, information is obtained from answers to questions concerning the consumption (or lack thereof) of different food items during the week preceding the interview. For the items eaten, the frequency (number of times within the past week), the origin (own harvest vs markets vs donation) and the amount spent are also asked.

It turns out that cereals are the most common food eaten by the households, in their different forms. Cereals or tubers are eaten by all sampled households at least once a week, on average over six times a week; vegetables and milk are consumed at least once a week by $76 \%$ and by $20 \%$ of households, respectively. Pulses, fruits and meat or fish are consumed by less than $10 \%$. Treated households, after the project intervention, tend to consume cereals, vegetables and meat less frequently. On the contrary, consumption of fruits, oil and fats increases. Even the share of households that declare the consumption of vegetables, fruits, meat or fish at least once a week increases. However, this information should be jointly considered in order to have a clearer idea of the effect of the project on the households' nutritional status.

A proxy of the level of diet diversification is computed as the simple sum of food types (out of a list of 16 Ethiopian common items included in the questionnaire) which have been eaten at least once in the previous 7 days. Out of 16 types, the average is around 5 at the baseline (slightly higher in the treatment than in the control group), while it grows significantly to 7 and 6.3 at the follow-up in the treatment and control groups, respectively. We also compute the Household Dietary Diversity Score (HDDS) - developed by the Food and Nutrition Technical Assistance Project (FANTA) - which corresponds to the number of different food groups (out of 12), consumed over the past 7 days (Swindale and Bilinsky, 2006). The HDDS food groups are constructed as follows: main staples are disaggregated into two groups (cereals, and roots and tubers), meat, fish and eggs group is disaggregated into its three subgroups; and there is a group for "other foods" , such as condiments, coffee, or tea. The HDDS does not vary significantly between treatment and control group neither at the baseline, nor at the follow-up. 


\subsection{Results}

\subsubsection{Agricultural production and revenues from sale}

Table 5 reports the results related to agricultural production and revenues from sale. Within the DID evaluation exercise, column 1 reports ITT as described in (1), column 2 and 3 show the coefficient of interest described in (2). For what concerns the WVR exercise, column 4 and 5 report the ITT and LATE coefficients described in (3) and (4), respectively. The project induces a strongly significant increase in the share of farmers cultivating vegetables by over 33 percentage points, confirmed in all specifications. Such a result is likely to be driven by the introduction of the horticultural products promoted and distributed within the project intervention, as witnessed by the increase in farmers growing cabbage $(+22$ percentage points), carrot (over 50 percentage points), onion ( +28 percentage points), beet root (between 34 and 50 percentage points). The increase in the probability of growing fruits appears lower than vegetables, around 7 percentage points, but it is not confirmed in the within village analysis. In general, the project seems to contribute to a larger product differentiation, as the total number of cultivated products significantly increases by almost 2 items.

Evidence suggests that the number of households which does not sell any product to the market and uses it for self-consumption tends to increase significantly by a range between 8 and 19 percentage points. Concerning sales of products and consequent revenues, we observe a significant increase in the revenues from sale of vegetables, estimated around 150 and 200 birr (corresponding to 7.2-9.6 USD per harvest). We find suggestive evidence, not confirmed throughout all specifications, of increases in revenues from sale of cereals and decreases in revenues from sale of pulses and tubers. Overall, such effects lead to no significant changes in total revenues from sale of agricultural products.

The analysis of heterogeneous effects along different levels of owned land and wealth does not point to any significant difference between sub-samples.

It is worth noticing that the five different specifications provide rather similar results in terms of size of coefficients and statistical significance. In particular, in DID specifications no statistical significant difference arises from the comparison of coefficients, meaning that there were no observable relevant differences in outcomes depending on different project intensity. Moreover, ITT and biased ATT estimates are not significantly different from each other, indicating a relatively low level of endogenous unobservable selection.

Estimates from WVR are smaller than DID ones. The former indeed represent lower bounds, given the likely presence of positive spillover effects. ITT and LATE coefficients are relatively similar given the high explanatory

Results are not shown but are available upon request 
power of the instrument in the first step, being around 0.8 throughout the different specifications with a level of significance never above 0.01 .

\subsubsection{Food consumption and diet diversification}

Table 6 shows the estimated effects of the project on food consumption and diet diversification. There is no evidence of project impact on diet diversification, as measured by the number of food types eaten in the previous seven days and summarized in the HDDS. By looking at the effects for different food categories, we find that no relevant changes occur neither along the extensive nor in the intensive margin consistently across both estimation approaches. DID estimation suggests slight reductions in the frequency of cereals and milk uptake and an increase in the share of people consuming fruits, oil and fats. Such results, however, are not confirmed in the WVR design. It is worth pointing out that, assuming positive within village spillover effects, WVR provides overestimates of the treatment effect. The only significant effect arising from both specifications is the increase in the frequency of fruit consumption, in a range between 0.2 and 0.4 times per week.

\subsection{Discussion}

\subsubsection{Results discussion}

The project was successful in inducing changes as consequences of the activities proposed and inputs provided. In particular, we find that the number of households growing vegetables increases by about 30 percentage points, i.e. $78 \%$ increase compared to the situation at the baseline. This result, in line with the literature (Bushamuka et al., 2005; English and Badcock, 1998; Faber et al., 2002; Laurie and Faber, 2008; Olney et al., 2009), seems to explain a significant increase in revenues from sale of vegetables which is also found by Kumar and Quisumbing (2011). However, overall, such changes do not seem to influence in a relevant way the total revenues from sales of agricultural products, which remain very much anchored to the relevance of cereals and pulses. In terms of revenues from sales, cereals and pulses account for about $88 \%$ and $10 \%$ of the total, respectively. The role of vegetables seem very marginal, around $1 \%$ (the role of fruits is negligible). As a consequence of that, the assessment of project impact on households' economic sphere (Table 7) does not show particularly relevant results. The project does not impact on households' monthly expenditure and on none of its components, namely food, non-food, schooling, healthcare and agricultural expenditures. We do not find conclusive evidence of impacts on the share of people saving and on amounts saved. Other sources of saving and buffer stocks, such as

Results of the first steps are not shown, but are available upon request 
the purchase of cattle or other animals, do not significantly change as a consequence of project activities. We can reasonably rule out that the project caused a short-term raise in disposable income which could be used in expenditure for food, health, schooling or saving. Similar results are also found in the long-run in Kumar and Quisumbing (2011) where a home gardening project is found to have no impact on food and nonfood expenditure, total assets, land owned, and per capita household income.

Households' nutritional sphere does not seem to be affected by project activities. We do not find evidence of improvement in diet diversification, in terms of consumption of vegetables. While we find some indication of changes in the share of households consuming fruits and in the frequency of uptake, the size of the change remains quite small. This result is not surprising in the light of the fact that no storage of vegetable products is available in the area in terms of both processing and conservation. Due to the perishable nature of horticultural products and the impossibility to rely on multiple cycles every year (no irrigation is available and agriculture is mostly rain fed), benefits from horticultural production, both in terms of diet improvement and income generation, can only be considered for a small fraction of the year. This is also found in Hirvonen et al. (2015). Moreover, we cannot rule out that impacts occurred for some particular categories of individuals living in the household, although the overall effect was insignificant, as in Quisumbing and Kumar (2011).

Although our endline survey occurred in a period relatively far from the harvest of the newly introduced horticultural products, our data reveal that the majority of such products has been allocated to households' consumption. Almost $40 \%$ and $60 \%$ of the households used all vegetables and all fruits harvested exclusively for self-consumption, respectively. The remaining $60 \%$ and $40 \%$ sold part of their fruits and vegetables to the market, respectively. This result seems to suggest that, in line with Bushamuka et al. (2005), household beneficiaries could, in principle, generate small income by selling part of their garden production to the market. No households decided to sell on the market the entire production of vegetables and fruits. When looking at the products introduced by the project, the pattern is even more evident. Among 70 and $80 \%$ of the households that had actually grown vegetables and fruits promoted by the project used the entire amount harvested for self-consumption. It is likely that such increase in self-consumption of new horticultural products have contributed to short-term improvements in diet diversification, which the timing of our survey prevents from detecting. This result is confirmed in other studies on home-gardening interventions (Faber et al., 2002; Laurie and Faber, 2008; Olney et al., 2009). 


\subsubsection{Study limitations and robustness checks}

Measurement errors are a first source of concerns given that the data collection process is particularly difficult in development contexts, due to, for example, respondents' low levels of education, recall bias, misunderstanding caused by linguistic barriers (given the different local dialects present in the area) or purposely misreporting in the expectation of receiving future support. However, it shall be noted that such issues, if any, should not be distributed in a systematically different manner between treatment and control groups, so that they should not contribute to bias the results. Despite this fact, self-reported values of land extensions do not seem always compatible with the amount of harvest declared, given the regional level of productivity. Thus, we decided not to consider any measure of productivity (like yields per hectare), given the high level of uncertainty in the measure of land extension by each crop. Instead, we rely more on estimates of harvested quantities, as for many products standards of sales and storing exist and are easier to recall (for example corn is stored and sold in sacks of fixed weight). We are unable to rigorously evaluate changes induced by the project in productivity and labor supply within households; we have only indications of an overall increase of the weekly time dedicated to farming. Such an increase is mostly covered by the household head and wife, when present. Qualitative evidence reveals that all family members take care of the vegetable garden, although this activity is mostly carried out by women, as the garden is normally realized in the proximity of the house. Conversely, men are usually farming cash crops in the larger fields, not necessarily close to the house. As a consequence of these limits in calculating inputs and productivity, we are unable to rigorously assess the profitability of growing horticultural products, in relation to local market prices.

In general, the very early endline survey (less than one year after project implementation) can only capture short-term impacts, leaving out possible longer term effects. Consequently, we should take this into consideration in the evaluation of the chain of changes, whose full development may require several years.

Concerning methodology, both estimation approaches present limits related to the assumptions made or to unobservable factors which may bias the estimates of impacts. A first possible threat to the validity of the DID estimation exercise lies in the possible presence of sample contamination through spillover effects from households in the treatment village to those in the control one. However, since only one household in Alemtena declared that they knew one of the project beneficiaries in Ropi and no household living in Alemtena has visited the show gardens in Ropi, we can rule out spillover effects across villages as a source of identification concern. The second source of concern is related to the DID identifying assumption for which unobservable differences between treatment and control samples are 
supposed to remain constant over time. In fact, the assumption implies the absence of village-specific shocks, while the very limited number of villages in the treatment and control groups prevents from disentangling village-specific shocks from treatment effects. That said, exposure to shocks does not seem very different for the two villages, given their relative proximity. We look at households exposure to negative shocks occurring between the two rounds of surveys across the two villages, we find that about $50 \%$ of households in Ropi experienced some type of shock, while about 35\% in Alemtena (the difference is significant at 1\%). However, by decomposing the previous variable for each type of shock, among a list of 13 types, we find that differences across samples are significant only for share of households experiencing flood (5\% in Ropi, $0 \%$ in Alemtena), heavy rains preventing work ( $8 \%$ vs $0 \%$ ), increase in price of inputs ( $8 \%$ vs $2 \%$ ). Overall, the presence of negative shocks to a larger extent in the treatment village may affect the evaluation exercise by underestimating impacts.

In order to better compare treatment and control groups, we repeat the DID exercise, by using propensity score matching. This non-parametric method allows us to balance the two samples along several observable covariates. We construct a propensity score (Rosenbaum and Rubin, 1983) considering variables affecting both treatment and outcome Heckman et al. (1999), fixed over time, and found to be relevant in previous research. Following Bryson et al. (2002), we preferred to estimate a more conservative model with a short list of covariates. More specifically, the estimated propensity score includes indicators of family wealth (the amount of land owned by the household, wealth index and income quintiles), head's characteristics (whether the head is female, whether he/she lives in couple, his/her age, his/her grade of schooling and whether he is a farmer or a model farmer) and indicators of participation in the program and in social activities as described in section 2. We implement different matching algorithms, namely the nearest neighbor bias corrected matching estimator $(\mathrm{k}=1)$ put forward by Abadie and Imbens (2008), the bootstrapped kernel matching estimator by Becker et al. (2002), the nearest neighbor $(k=4)$ matching with caliper, biweighted kernel matching and radius matching with caliper (Leuven and Sianesi, 2014). In all exercises we impose common support and sample balancing appears satisfactory (the absolute standardized bias is less than 5\% for all covariates and the mean propensity score is not different for treated and control individuals in each of six blocks the distribution has been divided in). Results are reported in tables 8 and 9 in the Appendix and appear in line with estimations obtained with OLS.

See (Caliendo and Kopeinig, 2008) for a discussion of trade-off among different matching algorithms

Absolute standardized bias indicates the average percentage difference between treated and control individuals after matching. The literature indicates $5 \%$ as the rule of thumb for a satisfactory balancing 
Given our small sample and the significant differences between treated and control households in our WVR design, as depicted in column 6 of table 1, we re-weight the observations of our control sub-sample in order to perfectly balance covariate distributions in the treated and control groups along the first three sample moments (i.e. mean, variance and skewness), turning to entropy balancing (Hainmueller, 2011; Hainmueller and Xu, 2013). It turns out that none of the results as regards the treatment depend on re-weighting our sample. Results are available upon request.

\section{Conclusions}

We assess the impact of an agricultural extension project implemented in a rural village in Ethiopia between 2013 and 2014 and aimed at introducing the cultivation of horticultural gardens along with innovative techniques, products and inputs. The intervention was targeted to vulnerable households. In accordance with the project's theory of change, our main outcomes of interest is the level of adoption of new horticultural products. As a consequence of adoption, we also assess project impacts on the level of revenues from sale and diet diversification. We find that the project contributes to production diversification as the number of households growing vegetables increases by about 30 percentage points. Overall, such changes do not seem to influence in a relevant way the total revenues from sales of agricultural products, which remain very much anchored to the relevance of cereals and pulses. The results suggest that extension projects similar to the one implemented in the area are an effective strategy for the introduction of vegetables and fruits through home gardens. However, the impact of vegetable sales from small land extensions, as proposed by the project, remains secondary in terms of share of revenues compared to the role of cereals and pulses and does not impact on the total amount of revenues from sales. Although we do not find significant changes in the diet diversification level measured at the time of our survey, we cannot conclude that the program failed to improve the households' nutritional status. The perishable nature of the products introduced and their seasonality, combined with the relatively small size of land dedicated to these crops, the absence of irrigation and adequate storing technologies are important barriers for the realization of multiple cultivation cycles and the consequent long-term effects on diet diversification. Arguably, better results would have been reached by teaching basic storage and irrigation techniques during the training sessions. 


\section{Tables}

Table 1: Summary Statistics

\begin{tabular}{lccccc}
\hline \hline & $(1)$ & $(2)$ & $(3)$ & $(4)$ & $(5)$ \\
\hline & $\begin{array}{c}\text { Ropi } \\
(\mathrm{R})\end{array}$ & $\begin{array}{c}\text { Alemtena } \\
(\mathrm{A})\end{array}$ & $\begin{array}{c}\text { Ropi C. } \\
(\mathrm{RC})\end{array}$ & $(\mathrm{R}-\mathrm{A})$ & $(\mathrm{R}-\mathrm{RC})$ \\
\hline HH Characteristics & & & & & \\
HH size & 6.46 & 6.06 & 6.16 & $0.40^{* * *}$ & $-0.30^{* *}$ \\
N.children less than 5 & 1.38 & 1.40 & 1.13 & -0.02 & $-0.25^{* *}$ \\
Size of own land & 0.77 & 0.92 & 0.63 & $-0.15^{* * *}$ & $-0.14^{* *}$ \\
Head characteristics & & & & & \\
Head is female & 0.19 & 0.18 & 0.12 & 0.01 & $-0.072^{*}$ \\
Head lives in couple & 0.87 & 0.83 & 0.82 & 0.04 & -0.04 \\
Age of head & 39.97 & 34.79 & 38.98 & $5.18^{* * *}$ & -0.99 \\
Head school grade & 1.59 & 1.96 & 1.61 & -0.37 & 0.02 \\
Head is a model farmer & 0.09 & 0.13 & 0.06 & $-0.047^{*}$ & -0.03 \\
Head is farmer or breeder & 0.90 & 0.88 & 0.88 & 0.02 & -0.02 \\
\hline Household monthly income & 454.36 & 330.59 & & $123.8^{* * *}$ & \\
Wealth Index & 0.07 & -0.06 & & 0.13 & \\
\hline Benefit Support Program & 0.53 & 0.80 & 0.16 & $-0.27^{* * *}$ & $-0.37^{* * *}$ \\
At least one visit from DA & 0.90 & 0.93 & 1.00 & -0.03 & $0.095^{* * *}$ \\
\hline Participation in CBO & 0.88 & 0.70 & 0.91 & $0.18^{* * *}$ & 0.03 \\
Know model farmer & 0.81 & 0.91 & 0.75 & $-0.098^{* * *}$ & -0.06 \\
\hline \hline Observations & 242 & 239 & 121 & 481 & 363 \\
\hline
\end{tabular}

Note: $*$ denotes significance at 0.10 level $(* *$ at $0.05, * * *$ at 0.01$)$. 


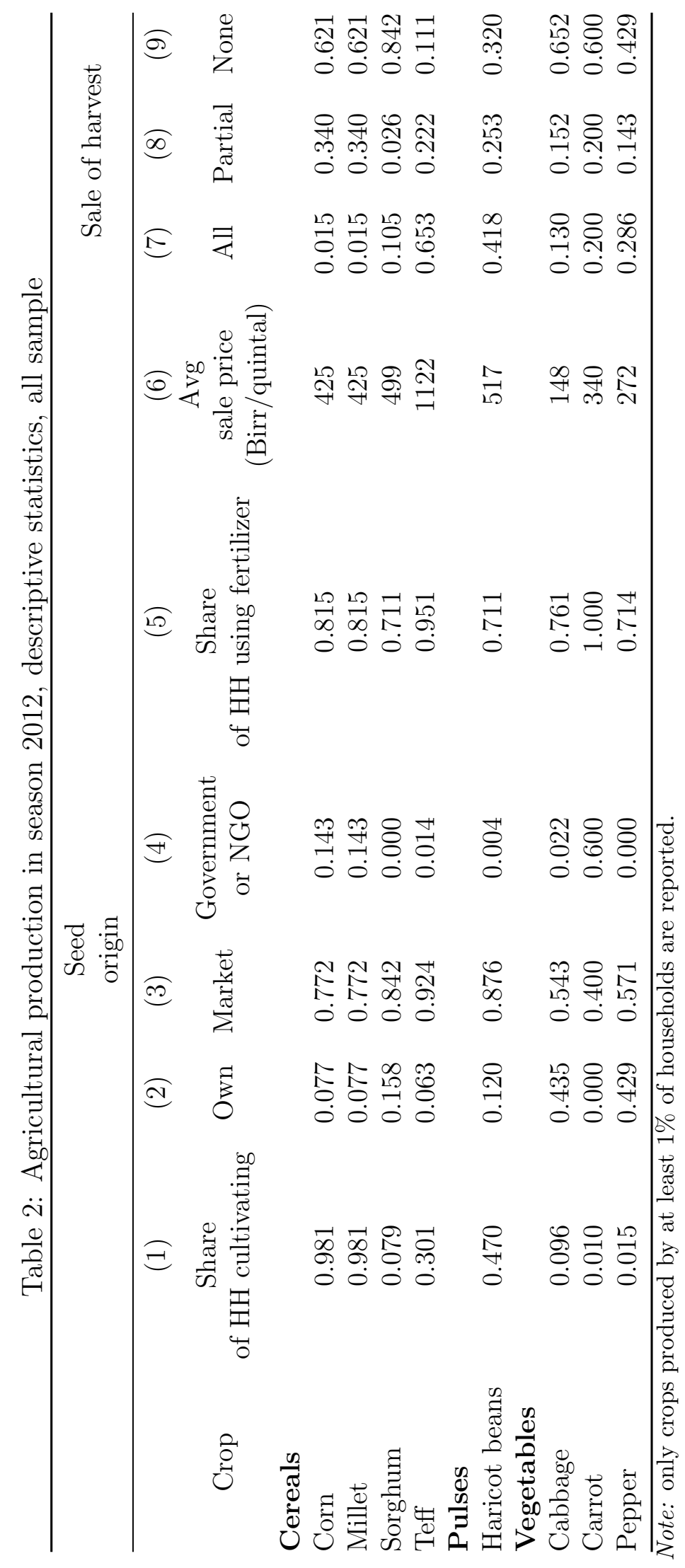




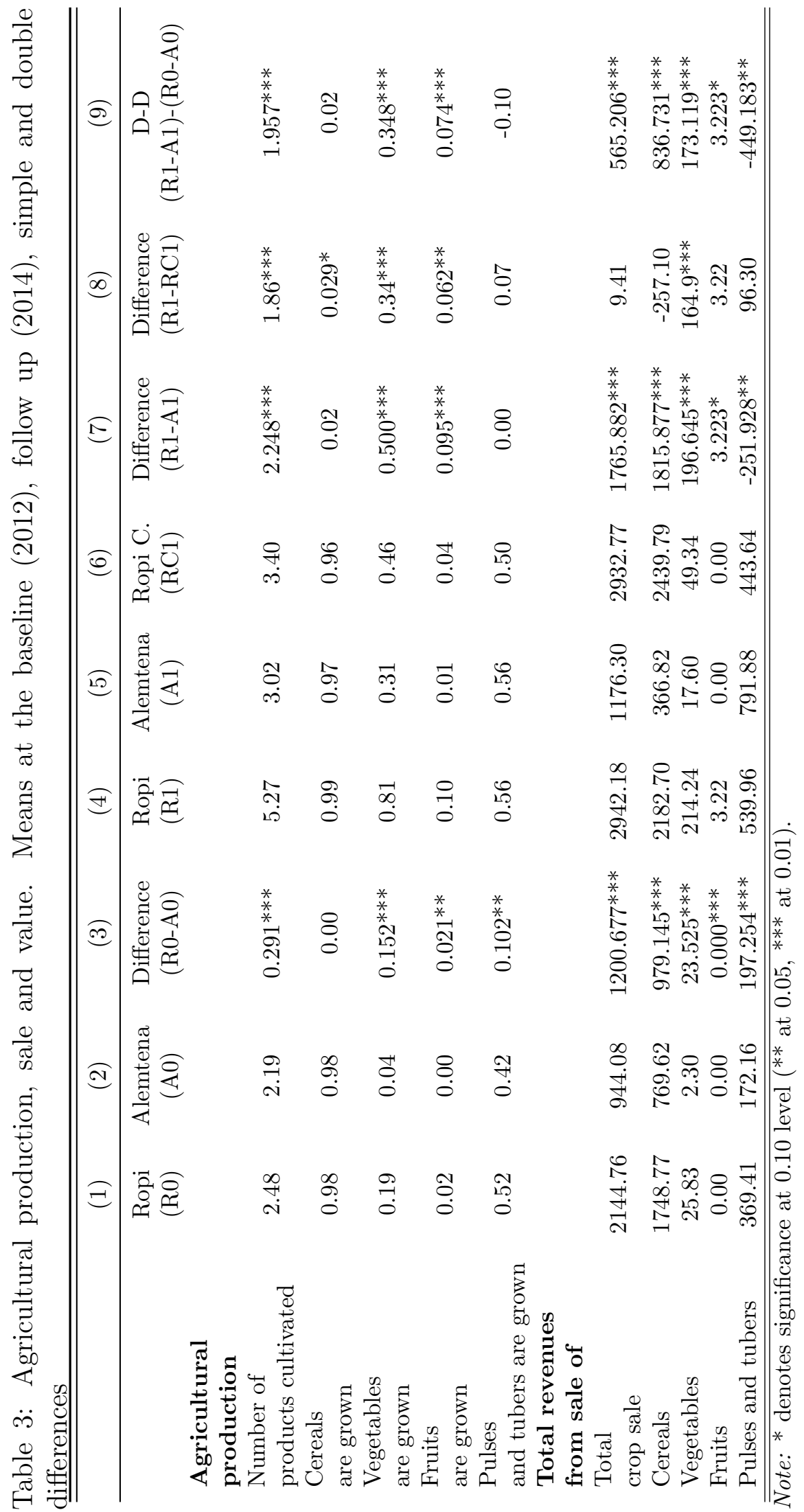




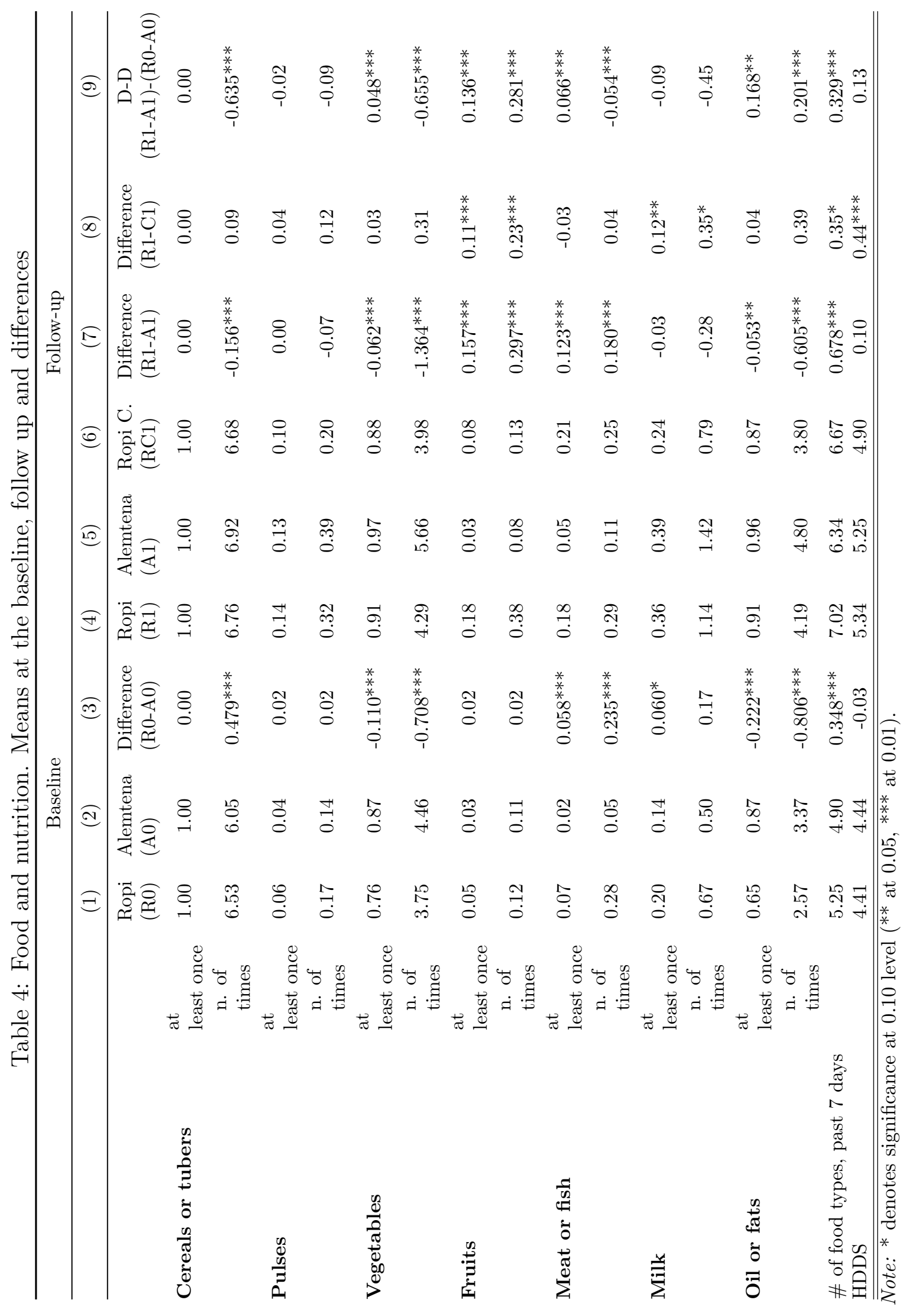


Table 5: Project effects on agricultural production DID (Ropi vs Alemtena) and within village randomization (Ropi beneficiaries vs Ropi control)

\begin{tabular}{|c|c|c|c|c|c|}
\hline & \multicolumn{3}{|c|}{ DID } & \multicolumn{2}{|c|}{ WVR } \\
\hline & \multirow[t]{2}{*}{ ITT } & \multicolumn{2}{|c|}{$\mathrm{ATT}^{*}$} & \multirow[t]{2}{*}{ ITT } & \multirow[t]{2}{*}{ LATE } \\
\hline & & Full & Partial & & \\
\hline & (1) & $(2)$ & (3) & $(4)$ & $(5)$ \\
\hline \multicolumn{6}{|l|}{ Agricultural production } \\
\hline \multirow[t]{2}{*}{ Cereals are grown } & 0.021 & 0.013 & 0.024 & 0.023 & 0.027 \\
\hline & 0.017 & 0.017 & 0.020 & 0.017 & 0.021 \\
\hline \multirow[t]{2}{*}{ Vegetables are grown } & $0.348^{* * *}$ & $0.331^{* * *}$ & $0.418^{* * *}$ & $0.338^{* *}$ & $0.386^{* * *}$ \\
\hline & 0.048 & 0.052 & 0.054 & 0.057 & 0.062 \\
\hline \multirow[t]{2}{*}{ Fruits are grown } & $0.074^{* * *}$ & $0.081^{* * *}$ & $0.072^{* *}$ & 0.024 & 0.027 \\
\hline & 0.022 & 0.027 & 0.036 & 0.024 & 0.041 \\
\hline \multirow[t]{2}{*}{ Pulses and tubers are grown } & -0.101 & -0.084 & 0.049 & 0.018 & 0.021 \\
\hline & 0.062 & 0.066 & 0.075 & 0.063 & 0.072 \\
\hline \multirow{2}{*}{$\begin{array}{l}\text { Total number of } \\
\text { cultivated products }\end{array}$} & $1.957^{* * *}$ & $1.913^{* * *}$ & $2.327^{* * *}$ & $1.581^{* * *}$ & $1.806^{* * *}$ \\
\hline & 0.191 & 0.226 & 0.252 & 0.207 & 0.296 \\
\hline \multicolumn{6}{|l|}{$\begin{array}{l}\text { Products introduced } \\
\text { by the project }\end{array}$} \\
\hline Cabbage is grown & $\begin{array}{c}0.261^{* * * *} \\
0.049\end{array}$ & $\begin{array}{l}0.220^{* * *} \\
0.055\end{array}$ & $\begin{array}{c}0.355^{* * * *} \\
0.061\end{array}$ & $\begin{array}{c}0.219 * * * \\
0.062\end{array}$ & $\begin{array}{l}0.265^{* * *} \\
0.070\end{array}$ \\
\hline Carrot is grown & $\begin{array}{c}0.587^{* * *} \\
0.033\end{array}$ & $\begin{array}{c}0.603^{* * *} \\
0.041\end{array}$ & $\begin{array}{c}0.598^{* * *} \\
0.055\end{array}$ & $\begin{array}{c}0.480^{* * *} \\
0.049\end{array}$ & $\begin{array}{c}0.561^{* * *} \\
0.062\end{array}$ \\
\hline Onion is grown & $\begin{array}{c}0.285^{* * * *} \\
0.030\end{array}$ & $\begin{array}{c}0.307 * * * \\
0.037\end{array}$ & $\begin{array}{c}0.283^{* * *} \\
0.052\end{array}$ & $\begin{array}{c}0.189^{* * *} \\
0.040\end{array}$ & $\begin{array}{c}0.243^{* * *} \\
0.057\end{array}$ \\
\hline \multirow[t]{2}{*}{$\begin{array}{l}\text { Beet root is } \\
\text { grown }\end{array}$} & $0.496^{* * *}$ & $0.507^{* * *}$ & $0.498^{* * *}$ & $0.342^{* * *}$ & $0.405^{* * *}$ \\
\hline & 0.032 & 0.042 & 0.059 & 0.054 & 0.065 \\
\hline Papaya is grown & $\begin{array}{c}0.050 * * * \\
0.018\end{array}$ & $\begin{array}{c}0.061^{* * *} \\
0.023\end{array}$ & $\begin{array}{l}0.034 \\
0.026\end{array}$ & $\begin{array}{c}0.030^{* *} \\
0.014\end{array}$ & $\begin{array}{l}0.033 \\
0.031\end{array}$ \\
\hline $\begin{array}{l}\text { Entire production } \\
\text { for self-consumption }\end{array}$ & $0.191^{* * *}$ & $0.157^{* * *}$ & $0.197^{* * *}$ & $0.076^{* *}$ & $0.087^{* *}$ \\
\hline Cereals & $\begin{array}{c}0.047 \\
836.73^{* *} \\
368.332\end{array}$ & $\begin{array}{c}0.046 \\
1306.22^{* * *} \\
431.138\end{array}$ & $\begin{array}{c}0.054 \\
933.69^{*} \\
509.421\end{array}$ & $\begin{array}{c}0.030 \\
-591.34 \\
610.745\end{array}$ & $\begin{array}{c}0.036 \\
-675.52 \\
586.917\end{array}$ \\
\hline Vegetables & $\begin{array}{c}173.11^{* * *} \\
35.030\end{array}$ & $\begin{array}{c}171.58^{* * *} \\
41.927\end{array}$ & $\begin{array}{c}220.14^{* * * *} \\
61.208\end{array}$ & $\begin{array}{c}145.51^{* * *} \\
39.826\end{array}$ & $\begin{array}{c}166.23^{* * *} \\
62.164\end{array}$ \\
\hline Fruits & $\begin{array}{c}3.223^{*} \\
1.741\end{array}$ & $\begin{array}{l}3.832^{*} \\
2.313\end{array}$ & $\begin{array}{l}1.952 \\
1.944\end{array}$ & $\begin{array}{l}0.958 \\
0.954\end{array}$ & $\begin{array}{l}1.094 \\
3.297\end{array}$ \\
\hline Pulses and tubers & $\begin{array}{c}-449.18^{* * *} \\
128.007\end{array}$ & $\begin{array}{c}-251.37^{*} \\
145.625\end{array}$ & $\begin{array}{c}-418.02^{* * *} \\
126.842\end{array}$ & $\begin{array}{c}45.17 \\
116.524\end{array}$ & $\begin{array}{c}51.60 \\
144.583\end{array}$ \\
\hline \multirow{2}{*}{$\begin{array}{l}\text { Total revenues } \\
\text { from crop sale }\end{array}$} & 565.206 & $1233.047^{* *}$ & 737.387 & -397.719 & -454.335 \\
\hline & 413.917 & 483.916 & 552.985 & 638.953 & 626.535 \\
\hline Observations & 962 & 962 & 962 & 361 & 361 \\
\hline
\end{tabular}

Note: the effects of the program on the variable reported in rows are shown with robust standard errors reported under the coefficient. DID regressions include the set of controls as described in section $3.1{ }^{*}$ denotes significance at 0.10 level $\left(* *\right.$ at $0.05,{ }^{* * *}$ at 0.01$)$. 
Table 6: Project effects on food consumption and diet diversification. DID (Ropi vs Alemtena) and within village randomization (Ropi beneficiaries vs Ropi control)

\begin{tabular}{|c|c|c|c|c|c|c|}
\hline & & \multicolumn{3}{|c|}{ DID } & \multicolumn{2}{|c|}{ WVR } \\
\hline & & \multirow[t]{2}{*}{ ITT } & \multicolumn{2}{|c|}{ ATT $^{*}$} & \multirow[t]{2}{*}{ ITT } & \multirow[t]{2}{*}{ LATE } \\
\hline & & & Full & Partial & & \\
\hline & & (1) & $(2)$ & $(3)$ & (4) & (5) \\
\hline \multirow{2}{*}{\multicolumn{2}{|c|}{ N. of food types, past 7 days }} & $0.329^{*}$ & $0.335^{*}$ & 0.410 & 0.060 & 0.066 \\
\hline & & 0.192 & 0.196 & 0.256 & 0.241 & 0.252 \\
\hline \multirow[t]{3}{*}{ HDDS } & & 0.126 & 0.207 & 0.111 & 0.235 & 0.257 \\
\hline & & 0.128 & 0.128 & 0.174 & 0.149 & 0.163 \\
\hline & & 0.044 & 0.047 & 0.052 & 0.039 & 0.053 \\
\hline \multicolumn{7}{|l|}{ Food categories } \\
\hline \multirow[t]{4}{*}{ Cereals } & at least once & 0.000 & 0.000 & 0.000 & 0.000 & 0.000 \\
\hline & & 0.000 & 0.000 & 0.000 & 0.000 & 0.000 \\
\hline & n. of times & $-0.635^{* * *}$ & $-0.596 * * *$ & $-0.608^{* * *}$ & -0.022 & -0.025 \\
\hline & & 0.125 & 0.120 & 0.149 & 0.102 & 0.114 \\
\hline \multirow[t]{4}{*}{ Pulses } & at least once & -0.022 & -0.010 & -0.056 & -0.017 & -0.023 \\
\hline & & 0.036 & 0.040 & 0.044 & 0.042 & 0.048 \\
\hline & n. of times & -0.086 & -0.116 & $-0.234^{*}$ & 0.039 & 0.045 \\
\hline & & 0.118 & 0.136 & 0.132 & 0.095 & 0.143 \\
\hline \multirow[t]{4}{*}{ Vegetables } & at least once & 0.048 & 0.027 & $0.095^{* *}$ & 0.013 & 0.015 \\
\hline & & 0.041 & 0.043 & 0.044 & 0.038 & 0.045 \\
\hline & n. of times & $-0.655^{* *}$ & $-0.622^{* *}$ & -0.375 & -0.097 & -0.144 \\
\hline & & 0.274 & 0.283 & 0.303 & 0.236 & 0.298 \\
\hline \multirow[t]{4}{*}{ Fruits } & at least once & $0.136^{* * *}$ & $0.122^{* * *}$ & $0.223^{* * *}$ & 0.058 & 0.069 \\
\hline & & 0.032 & 0.035 & 0.052 & 0.043 & 0.052 \\
\hline & n. of times & $0.281 * * *$ & $0.231^{* *}$ & $0.449^{* * *}$ & $0.193^{* *}$ & 0.178 \\
\hline & & 0.096 & 0.097 & 0.131 & 0.092 & 0.115 \\
\hline \multirow[t]{4}{*}{ Meat } & at least once & $0.066^{*}$ & $0.083^{* *}$ & 0.069 & -0.017 & -0.020 \\
\hline & & 0.034 & 0.039 & 0.049 & 0.047 & 0.049 \\
\hline & n. of times & -0.054 & -0.058 & -0.159 & 0.026 & 0.029 \\
\hline & & 0.101 & 0.124 & 0.112 & 0.067 & 0.109 \\
\hline \multirow[t]{4}{*}{ Milk } & at least once & -0.086 & -0.044 & -0.076 & 0.052 & 0.048 \\
\hline & & 0.053 & 0.056 & 0.065 & 0.058 & 0.066 \\
\hline & n. of times & $-0.445^{* *}$ & -0.267 & $-0.405^{*}$ & 0.146 & 0.116 \\
\hline & & 0.207 & 0.218 & 0.236 & 0.177 & 0.240 \\
\hline \multirow[t]{4}{*}{ Oils and fats } & at least once & $0.168 * * *$ & $0.166^{* * *}$ & $0.180^{* * *}$ & -0.007 & -0.004 \\
\hline & & 0.043 & 0.044 & 0.047 & 0.040 & 0.045 \\
\hline & n. of times & 0.201 & $0.441^{*}$ & 0.384 & -0.082 & -0.123 \\
\hline & & 0.257 & 0.265 & 0.305 & 0.240 & 0.311 \\
\hline Observations & & 962 & 962 & 962 & 361 & 361 \\
\hline
\end{tabular}

Note: the effects of the program on the variable reported in rows are shown with robust standard errors reported under the coefficient. DID regressions include the set of controls as described in section 3.1. ${ }^{*}$ denotes significance at 0.10 level $(* *$ at $0.05, * * *$ at 0.01$)$. 
Table 7: Project effects on expenditure and savings DID (Ropi vs Alemtena) and within village randomization (Ropi beneficiaries vs Ropi control)

\begin{tabular}{|c|c|c|c|c|c|}
\hline & \multicolumn{3}{|c|}{ DID } & \multicolumn{2}{|c|}{ WVR } \\
\hline & \multirow[t]{2}{*}{ ITT } & \multicolumn{2}{|c|}{$\mathrm{ATT}^{*}$} & \multirow[t]{2}{*}{ ITT } & \multirow[t]{2}{*}{ LATE } \\
\hline & & Full & Partial & & \\
\hline & (1) & $(2)$ & (3) & (4) & (5) \\
\hline \multirow[t]{2}{*}{ Total monthly expenditure } & 70.071 & 118.711 & 74.140 & 62.995 & 76.644 \\
\hline & 92.784 & 93.890 & 98.407 & 70.288 & 79.120 \\
\hline \multirow[t]{2}{*}{$\begin{array}{l}\text { Monthly food } \\
\text { expenditure }\end{array}$} & 121.632 & $154.359^{* *}$ & $140.304^{*}$ & -1.859 & 6.130 \\
\hline & 74.713 & 77.067 & 74.438 & 51.525 & 56.956 \\
\hline \multirow{2}{*}{$\begin{array}{l}\text { Total monthly } \\
\text { non-food expenditure }\end{array}$} & -27.681 & -22.679 & -49.332 & 1.451 & 2.616 \\
\hline & 30.115 & 29.631 & 33.707 & 30.395 & 34.311 \\
\hline \multirow{2}{*}{$\begin{array}{l}\text { Monthly school } \\
\text { expenditure }\end{array}$} & -4.003 & -3.062 & -1.428 & -0.869 & -0.830 \\
\hline & 3.293 & 2.955 & 3.571 & 1.777 & 2.132 \\
\hline \multirow{2}{*}{$\begin{array}{l}\text { Monthly } \\
\text { healthcare expenditure }\end{array}$} & 1.307 & 6.259 & 3.386 & $14.695^{*}$ & 17.508 \\
\hline & 8.747 & 9.480 & 9.592 & 8.127 & 11.576 \\
\hline \multirow[t]{2}{*}{$\begin{array}{l}\text { Monthly } \\
\text { agriculture expenditure }\end{array}$} & $-16.802^{*}$ & -15.103 & -17.007 & 14.842 & 15.880 \\
\hline & 9.493 & 10.455 & 12.362 & 9.586 & 11.757 \\
\hline \multirow[t]{2}{*}{$\begin{array}{l}\text { Other } \\
\text { expenditures }\end{array}$} & -3.449 & 0.217 & -1.839 & $30.904^{* * *}$ & $31.192^{* *}$ \\
\hline & 12.772 & 13.282 & 16.199 & 10.909 & 14.848 \\
\hline \multirow[t]{2}{*}{ Cash saving } & 0.022 & -0.038 & -0.017 & $0.104^{* *}$ & $0.129^{* *}$ \\
\hline & 0.048 & 0.053 & 0.066 & 0.051 & 0.063 \\
\hline \multirow[t]{2}{*}{ Amount saved } & 73.579 & 81.810 & 81.121 & -132.094 & -150.898 \\
\hline & 56.773 & 63.538 & 98.003 & 147.157 & 152.323 \\
\hline Observations & 962 & 962 & 962 & 361 & 361 \\
\hline
\end{tabular}

Note: the effects of the program on the variable reported in rows are shown with robust standard errors reported under the coefficient. DID regressions include the set of controls as described in section 3.1. ${ }^{*}$ denotes significance at 0.10 level $\left(* *\right.$ at $0.05,{ }^{* * *}$ at 0.01$)$. 


\section{Appendix}

Table 8: Project effect on agricultural production and household expenditures, Propensity Score Matching Estimation

\begin{tabular}{|c|c|c|c|c|c|}
\hline & (1) & (2) & (3) & (4) & (5) \\
\hline Outcome & Nearest Neighbor & Kernel & Caliper & Biweighted kernel & Radius \\
\hline \multicolumn{6}{|l|}{ Agricultural Production } \\
\hline \multirow[t]{2}{*}{ Cereals are grown } & 0.021 & 0.021 & 0.004 & 0.021 & 0.021 \\
\hline & 0.014 & 0.013 & 0.009 & 0.014 & 0.014 \\
\hline \multirow[t]{2}{*}{ Vegetables are grown } & $0.348^{* * *}$ & $0.348^{* * *}$ & $0.866^{* * *}$ & $0.348^{* * *}$ & $0.348^{* * *}$ \\
\hline & 0.048 & 0.047 & 0.252 & 0.048 & 0.048 \\
\hline \multirow[t]{2}{*}{ Fruits are grown } & $0.074^{* * *}$ & $0.074^{* * *}$ & $0.083^{* * *}$ & $0.074^{* * *}$ & $0.074^{* * *}$ \\
\hline & 0.02 & 0.02 & 0.02 & 0.02 & 0.02 \\
\hline \multirow[t]{2}{*}{ Pulses are grown } & $-0.101^{*}$ & $-0.101^{*}$ & $-0.709^{* * *}$ & $-0.101^{*}$ & $-0.101^{*}$ \\
\hline & 0.055 & 0.064 & 0.254 & 0.061 & 0.061 \\
\hline \multirow[t]{2}{*}{ \# of cultivated products } & $1.957 * * *$ & $1.957 * * *$ & $2.035^{* * *}$ & $1.957^{* * *}$ & $1.957^{* * *}$ \\
\hline & 0.176 & 0.188 & 0.648 & 0.182 & 0.182 \\
\hline \multicolumn{6}{|l|}{$\begin{array}{l}\text { Products introduced } \\
\text { by the project }\end{array}$} \\
\hline \multirow[t]{2}{*}{ Papaya is grown } & $0.05^{* * *}$ & $0.05^{* * *}$ & $0.054^{* * *}$ & 0.05 & $0.05^{* * *}$ \\
\hline & 0.018 & 0.018 & 0.017 & 0.017 & 0.017 \\
\hline \multirow[t]{2}{*}{ Cabbage is grown } & $0.261^{* * *}$ & $0.261^{* * *}$ & $0.521^{* * *}$ & $0.261^{* * *}$ & $0.261^{* * *}$ \\
\hline & 0.050 & 0.051 & 0.037 & 0.049 & 0.049 \\
\hline \multirow[t]{2}{*}{ Carrot is grown } & $0.587^{* * *}$ & $0.587^{* * *}$ & $0.595^{* * *}$ & $0.587^{* * *}$ & $0.587^{* * *}$ \\
\hline & 0.032 & 0.033 & 0.032 & 0.033 & 0.033 \\
\hline \multirow[t]{2}{*}{ Onion is grown } & $0.285^{* * *}$ & $0.285^{* * *}$ & $0.285^{* * *}$ & $0.285^{* * *}$ & $0.285^{* * *}$ \\
\hline & 0.030 & 0.029 & 0.029 & 0.029 & 0.029 \\
\hline \multirow[t]{2}{*}{ Beet root is grown } & $0.496^{* * *}$ & $0.496^{* * *}$ & $0.496^{* * *}$ & $0.496^{* * *}$ & $0.496^{* * *}$ \\
\hline & 0.034 & 0.030 & 0.032 & 0.032 & 0.032 \\
\hline \multicolumn{6}{|l|}{$\begin{array}{l}\text { Total revenues } \\
\text { from sale of }\end{array}$} \\
\hline \multirow[t]{2}{*}{ Cereals } & $836.731^{* *}$ & $836.731^{* *}$ & $933.928^{*}$ & $836.731^{* *}$ & $836.731^{* *}$ \\
\hline & 419.796 & 396.388 & 493.135 & 408.045 & 408.045 \\
\hline \multirow{2}{*}{ Vegetables } & $173.119^{* * *}$ & $173.119^{* * *}$ & $300.917^{* *}$ & $173.119^{* * *}$ & $173.119^{* * *}$ \\
\hline & 38.564 & 33.712 & 116.987 & 34.098 & 34.098 \\
\hline \multirow[t]{2}{*}{ Fruits } & $3.223^{*}$ & $3.223^{*}$ & $3.223^{*}$ & $3.223^{*}$ & $3.223^{*}$ \\
\hline & 1.647 & 1.738 & 1.737 & 1.737 & 1.737 \\
\hline \multirow[t]{2}{*}{ Pulses } & $-449.183^{* * *}$ & $-449.183^{* * *}$ & -804.455 & $-449.183^{* * *}$ & $-449.183^{* * *}$ \\
\hline & 123.811 & 122.351 & 827.649 & 127.011 & 127.011 \\
\hline \multirow[t]{2}{*}{ Crop sale } & 565.206 & 565.206 & 434.927 & 565.206 & 565.206 \\
\hline & 458.773 & 504.603 & 846.141 & 458.065 & 458.065 \\
\hline
\end{tabular}

Note: the effects of the program on the variable reported in rows are shown with robust standard errors reported under the coefficient. DID regressions include the set of controls as described in section 3.1. ${ }^{*}$ denotes significance at 0.10 level $\left(* *\right.$ at $0.05,{ }^{* * *}$ at 0.01$)$. 
Table 9: Project effect on nutrition, Propensity Score Matching Estimation

\begin{tabular}{|c|c|c|c|c|c|}
\hline & (1) & $(2)$ & $(3)$ & (4) & (5) \\
\hline Outcome & Nearest Neighbor & Kernel & Caliper & Biweighted kernel & Radius \\
\hline \multicolumn{6}{|l|}{ Nutrition } \\
\hline \multirow[t]{2}{*}{ \# of food types, past $7 \mathrm{~d}$} & $0.329^{*}$ & $0.329^{*}$ & $0.773^{*}$ & $0.329^{*}$ & $0.329 *$ \\
\hline & 0.183 & 0.198 & 0.432 & 0.186 & 0.186 \\
\hline \multirow[t]{2}{*}{ HDDS } & 0.126 & 0.126 & 0.438 & 0.126 & 0.126 \\
\hline & 0.124 & 0.119 & 0.304 & 0.128 & 0.128 \\
\hline \multicolumn{6}{|l|}{ At least once per week } \\
\hline \multirow[t]{2}{*}{ Eat cereals and tubers } & $0^{* * *}$ & $0^{* * *}$ & $0^{* * *}$ & $0^{* * *}$ & $0^{* * *}$ \\
\hline & 0 & 0 & 0 & 0 & 0 \\
\hline \multicolumn{6}{|l|}{ n. of times eaten } \\
\hline \multirow[t]{2}{*}{ cereals and tubers } & $-0.635^{* * *}$ & $-0.635^{* * *}$ & $0.231^{* * *}$ & $-0.635^{* * *}$ & $-0.635^{* * *}$ \\
\hline & 0.124 & 0.124 & 0.081 & 0.127 & 0.127 \\
\hline \multirow[t]{2}{*}{ Eat pulses } & -0.022 & -0.022 & $0.074^{* * *}$ & -0.022 & -0.022 \\
\hline & 0.037 & 0.036 & 0.026 & 0.035 & 0.035 \\
\hline \multirow[t]{2}{*}{ n. of times eaten pulses } & -0.09 & -0.09 & $0.153^{*}$ & -0.09 & -0.09 \\
\hline & 0.11 & 0.139 & 0.078 & 0.117 & 0.117 \\
\hline \multirow[t]{2}{*}{ Eat vegetables } & 0.048 & 0.048 & $0.145^{* * *}$ & 0.048 & 0.048 \\
\hline & 0.04 & 0.04 & 0.033 & 0.04 & 0.04 \\
\hline \multirow[t]{2}{*}{ n. of times eaten vegetables } & $-0.655^{* *}$ & $-0.655^{* *}$ & -0.455 & $-0.655^{* *}$ & $-0.655^{* *}$ \\
\hline & 0.286 & 0.727 & 1.1 & 0.27 & 0.27 \\
\hline \multirow[t]{2}{*}{ Eat fruits } & $0.136^{* * *}$ & $0.136^{* * *}$ & $0.136^{* * *}$ & $0.136^{* * *}$ & $0.136^{* * *}$ \\
\hline & 0.035 & 0.034 & 0.029 & 0.032 & 0.032 \\
\hline \multirow[t]{2}{*}{ n. of times eaten fruits } & $0.265^{* * *}$ & $0.265^{* * *}$ & $0.24^{* * *}$ & $0.265^{* * *}$ & $0.265^{* * *}$ \\
\hline & 0.087 & 0.094 & 0.073 & 0.095 & 0.095 \\
\hline \multirow[t]{2}{*}{ Eat meat/egg } & $0.066^{* *}$ & $0.066^{* *}$ & $0.103^{* * *}$ & $0.066^{* *}$ & $0.066^{* *}$ \\
\hline & 0.034 & 0.034 & 0.029 & 0.033 & 0.033 \\
\hline \multirow[t]{2}{*}{ n. of times eaten meat/egg } & -0.054 & -0.054 & 0.008 & -0.054 & -0.054 \\
\hline & 0.091 & 0.122 & 0.092 & 0.101 & 0.101 \\
\hline \multirow{2}{*}{ Eat milk } & $-0.086^{*}$ & $-0.086^{*}$ & -0.339 & $-0.086^{*}$ & $-0.086^{*}$ \\
\hline & 0.053 & 0.052 & 0.291 & 0.051 & 0.051 \\
\hline \multirow[t]{2}{*}{ n. of times eaten milk } & $-0.445^{* *}$ & $-0.445^{* *}$ & -0.029 & $-0.445^{* *}$ & $-0.445^{* *}$ \\
\hline & 0.194 & 0.181 & 0.317 & 0.193 & 0.193 \\
\hline \multirow[t]{2}{*}{ Eat oil/fats } & $0.168^{* * *}$ & $0.168^{* * *}$ & $0.26^{* * *}$ & $0.168^{* * *}$ & $0.168^{* * *}$ \\
\hline & 0.046 & 0.041 & 0.034 & 0.043 & 0.043 \\
\hline \multirow{2}{*}{ n. of times eaten oil/fats } & 0.201 & 0.201 & 0.628 & 0.201 & 0.201 \\
\hline & 0.272 & 0.26 & 1.241 & 0.26 & 0.26 \\
\hline
\end{tabular}

Note: the effects of the program on the variable reported in rows are shown with robust standard errors reported under the coefficient. DID regressions include the set of controls as described in section 3.1. ${ }^{*}$ denotes significance at 0.10 level $\left(* *\right.$ at $0.05,{ }^{* * *}$ at 0.01 ). 


\section{References}

Abadie, A. (2005). Semiparametric difference-in-differences estimators. The Review of Economic Studies, 72(1):1-19.

Abadie, A. and Imbens, G. W. (2008). On the failure of the bootstrap for matching estimators. Econometrica, 76(6):1537-1557.

Agency, E. C. S. (2014). National report. National report, ethiopian central statistical agency.

Aker, J. C. (2011). Dial a for agriculture: a review of information and communication technologies for agricultural extension in developing countries. Agricultural Economics, 42(6):631-647.

Anderson, J. R. and Feder, G. (2007). Agricultural Extension, volume 3 of Handbook of Agricultural Economics, chapter 44, pages 2343-2378. Elsevier.

Angrist, J. D., Imbens, G. W., and Rubin, D. B. (1996). Identification of causal effects using instrumental variables. Journal of the American statistical Association, 91(434):444-455.

Ashraf, N., Berry, J., and Shapiro, J. M. (2009a). Can higher prices stimulate product use? evidence from a field experiment in Zambia. Working paper, National Bureau of Economic Research.

Ashraf, N., Giné, X., and Karlan, D. (2009b). Finding missing markets (and a disturbing epilogue): Evidence from an export crop adoption and marketing intervention in Kenya. American Journal of Agricultural Economics, 91(4):973-990.

Barrett, C. B. and Carter, M. R. (2010). The power and pitfalls of experiments in development economics: Some non-random reflections. Applied Economic Perspectives and Policy, 32(4):515-548.

Becker, S. O., Ichino, A., et al. (2002). Estimation of average treatment effects based on propensity scores. The stata journal, 2(4):358-377.

Berti, P. R., Krasevec, J., and FitzGerald, S. (2004). A review of the effectiveness of agriculture interventions in improving nutrition outcomes. Public Health Nutrition, 7:599-609.

Birner, R., Davis, K., Pender, J., Nkonya, E., Anandajayasekeram, P., Ekboir, J., Mbabu, A., Spielman, D. J., Horna, D., Benin, S., and Cohen, M. (2009). From best practice to best fit: A framework for designing and analyzing pluralistic agricultural advisory services worldwide. The Journal of Agricultural Education and Extension, 15(4):341-355. 
Bryson, A., Dorsett, R., and Purdon, S. (2002). The use of propensity score matching in the evaluation of active labour market policies. Working paper.

Bushamuka, V. N., de Pee, S., Talukder, A., Kiess, L., Panagides, D., Taher, A., and Bloem, M. (2005). Impact of a homestead gardening program on household food security and empowerment of women in Bangladesh. Food $\&$ Nutrition Bulletin, 26(1):17-25.

Caliendo, M. and Kopeinig, S. (2008). Some practical guidance for the implementation of propensity score matching. Journal of economic surveys, $22(1): 31-72$.

Christiaensen, L. and Demery, L. (2007). Down to Earth. World Bank.

Conning, J. and Udry, C. (2007). Chapter 56 Rural Financial Markets in Developing Countries, volume 3 of Handbook of Agricultural Economics, pages 2857 - 2908. Elsevier.

Croppenstedt, A., Demeke, M., and Meschi, M. M. (2003). Technology adoption in the presence of constraints: the case of fertilizer demand in Ethiopia. Review of Development Economics, 7(1):58-70.

Davis, K., Nkonya, E., Kato, E., Mekonnen, D., Odendo, M., Miiro, R., and Nkuba, J. (2012). Impact of Farmer Field Schools on Agricultural Productivity and Poverty in East Africa. World Development, 40(2):402413.

Dercon, S., Gilligan, D. O., Hoddinott, J., and Woldehanna, T. (2009). The impact of agricultural extension and roads on poverty and consumption growth in fifteen Ethiopian villages. American Journal of Agricultural Economics, 91(4):1007-1021.

DFID (2014). Can agriculture interventions promote nutrition? DFID Evidence Papers.

English, R. and Badcock, J. (1998). A community nutrition project in Viet Nam: Effects on child morbidity. Food Nutrition and Agriculture, pages $15-21$.

Evenson, R. (2003). Crop variety improvement and its effect on productivity the impact of international agricultural research. CABI Pub.

Faber, M., Venter, S. L., and Benade, A. (2002). Increased vitamin a intake in children aged 2-5 years through targeted home-gardens in a rural South African community. Public health nutrition, 5(01):11-16. 
FAO, IFAD, and WFP (2014). State of food insecurity in the world 2014: strengthening the enabling environment for food security and nutrition. Food and Agriculture Organization of the United Nations, Rome.

Filmer, D. and Pritchett, L. H. (2001). Estimating wealth effects without expenditure data or tears: An application to educational enrollments in states of India. Demography, 38(1):115-132.

Fink, G., Jack, B. K., and Masiye, F. (2014). Seasonal credit constraints and agricultural labor supply: Evidence from zambia. Technical report.

Girard, A. W., Self, J. L., McAuliffe, C., and Olude, O. (2012). The effects of household food production strategies on the health and nutrition outcomes of women and young children: A systematic review. Paediatric and Perinatal Epidemiology, 26:205-222.

Godtland, E. M., Sadoulet, E., Janvry, A. D., Murgai, R., and Ortiz, O. (2004). The impact of farmer field schools on knowledge and productivity: A study of potato farmers in the Peruvian Andes. Economic Development and Cultural Change, 53:63-92.

Goldstein, M. and Udry, C. (2008). The profits of power: Land rights and agricultural investment in Ghana. Journal of Political Economy, 116(6):pp. 981-1022.

Hainmueller, J. (2011). Entropy balancing for causal effects: A multivariate reweighting method to produce balanced samples in observational studies. Political Analysis, page mpr025.

Hainmueller, J. and Xu, Y. (2013). Ebalance: A stata package for entropy balancing. Journal of Statistical Software, 54(7).

Heckman, J. J., Ichimura, H., and Todd, P. E. (1997). Matching as an econometric evaluation estimator: Evidence from evaluating a job training programme. The Review of Economic Studies, 64(4):pp. 605-654.

Heckman, J. J., LaLonde, R. J., and Smith, J. A. (1999). The economics and econometrics of active labor market programs. Handbook of labor economics, 3:1865-2097.

Heckman, J. J. and Robb, R. (1985). Alternative methods for evaluating the impact of interventions: An overview. Journal of econometrics, 30(1):239267.

Hirvonen, K., Taffesse, A. S., and Worku, I. (2015). Seasonality and household diets in Ethiopia:. Technical report. 
Jack, B. K. (2011). White paper prepared for the agricultural technology adoption initiative. Working paper.

Kazianga, H. and Udry, C. (2006). Consumption smoothing? livestock, insurance and drought in rural Burkina Faso. Journal of Development Economics, 79(2):413 - 446 .

Krishnan, P. and Patnam, M. (2014). Neighbors and extension agents in ethiopia: Who matters more for technology adoption? American Journal of Agricultural Economics, 96(1):308-327.

Kumar, N. and Quisumbing, A. R. (2011). Access, adoption, and diffusion: understanding the long-term impacts of improved vegetable and fish technologies in Bangladesh. Journal of Development Effectiveness, 3(2):193219.

Laurie, S. M. and Faber, M. (2008). Integrated community-based growth monitoring and vegetable gardens focusing on crops rich in $\beta$-carotene: Project evaluation in a rural community in the Eastern Cape, South Africa. Journal of the Science of Food and Agriculture, 88(12):2093-2101.

Leuven, E. and Sianesi, B. (2014). Psmatch2: Stata module to perform full mahalanobis and propensity score matching, common support graphing, and covariate imbalance testing. Statistical Software Components.

Maffioli, A., Ubfal, D., Baré, G. V., and Cerdán-Infantes, P. (2011). Extension services, product quality and yields: the case of grapes in Argentina. Agricultural Economics, 42(6).

Maffioli, A., Ubfal, D., Vazquez-Bare, G., and Cerdan-Infantes, P. (2013). Improving technology adoption in agriculture through extension services: evidence from Uruguay. Journal of Development Effectiveness, 5(1):64-81.

Malik, K. (2013). Human development report 2013: the rise of the South. Human progress in a diverse world. United Nations Development Programme.

Masset, E., Haddad, L., Cornelius, A., and Isaza-Castro, J. (2012). Effectiveness of agricultural interventions that aim to improve nutritional status of children: systematic review. BMJ, 344 .

Michael, G. and Lars Christian, M. (2013). Ethiopia - second economic update: laying the foundation for achieving middle income status. Working paper, World Bank. 
Olney, D. K., Talukder, A., Iannotti, L. L., Ruel, M. T., and Quinn, V. (2009). Assessing impact and impact pathways of a homestead food production program on household and child nutrition in Cambodia. Food 8 Nutrition Bulletin, 30(4):355-369.

Owens, T., Hoddinott, J., and Kinsey, B. (2003). The impact of agricultural extension on farm production in resettlement areas of Zimbabwe. Economic Development and Cultural Change, 51(2).

Praneetvatakul, S. and Waibel, H. (2008). A panel data model for the assessment of farmer field schools in Thailand, pages 137-151. Elsevier.

Quisumbing, A. R. and Kumar, N. (2011). Does social capital build women's assets? the long-term impacts of group-based and individual dissemination of agricultural technology in Bangladesh. Journal of Development Effectiveness, 3(2):220-242.

Rivera, W. M., Qamar, M. K., Van Crowder, L., et al. (2001). Agricultural and rural extension worldwide: options for institutional reform in the developing countries. FAO, Rome.

Romani, M. et al. (2003). The impact of extension services in times of crisis: Côte d'Ivoire (1997-2000). University of Oxford, Centre for the Study of African Economies.

Rosenbaum, P. R. and Rubin, D. B. (1983). The central role of the propensity score in observational studies for causal effects. Biometrika, 70(1):41-55.

Rosenzweig, M. R. and Wolpin, K. I. (1993). Credit market constraints, consumption smoothing, and the accumulation of durable production assets in low-income countries: Investment in bullocks in India. Journal of Political Economy, 101(2):223-44.

Ruel, M. T. and Alderman, H. (2013). Nutrition-sensitive interventions and programmes: how can they help to accelerate progress in improving maternal and child nutrition? The Lancet, 382(9891):536 - 551.

Swindale, A. and Bilinsky, P. (2006). Development of a universally applicable household food insecurity measurement tool: process, current status, and outstanding issues. The Journal of nutrition, 136(5):1449S-1452S.

Taye, H. (2013). Evaluating the impact of agricultural extension programmes in sub-Saharan Africa: Challenges and prospects. African Evaluation Journal, 1(1).

Udry, C. (2010). The economics of agriculture in Africa: Notes toward a research program. African Journal of Agricultural and Resource Economics, $5(1)$. 
Van der Ban, A. and Hawkins, H. (1996). Agricultural extension. Blackwell Science, Oxford Malden, MA.

Vyas, S. and Kumaranayake, L. (2006). Constructing socio-economic status indices: how to use principal components analysis. Health policy and planning, 21(6):459-468.

World Bank, T. (2007). World development report 2008 agriculture and development. World Bank Eurospan distributor, Washington, D.C. London. 